\title{
The Level of Ethical Sensitivity among Jordanian University Students According to their Educational Level \& Specialization
}

\author{
Bilal Adel Al-Kateeb ${ }^{1}$ \\ Fatima Raqqad $^{2}$ \\ Nisreen Shamayleh ${ }^{3}$ \\ Fatima Abdelhadi Zainelabdin ${ }^{4}$ \\ Amaal Al Masri ${ }^{5^{\star}}$
}

'Associate Professor, Princess Alia University College, Al Balqa Applied University, Amman, Jordan.

'Instructor, Princess Alia University College, Al-Balqa Applied University, Jordan.

${ }^{3.5}$ Assistant Professor, Princess Alia University College, Al Balqa Applied University, Amman, Jordan.

${ }^{5}$ Email:dr.amaalalmasri@yahoo.com

'Assistant Professor, Amman University College for Financial and Administrative Sciences, Al Balqa Applied

University, Amman, Jordan.

\begin{abstract}
This study aimed to investigate the level of ethical sensitivity among Princess Alia University College Students in Jordan and how this is influenced by their educational level and specialization. To achieve the objects of the study, the ethical sensitivity scale questionnaire (ESSQ) was used, as developed by Narvaez (2001). This was used to measure the moral sensitivity of adults and adolescents. It consists of (28) items in seven dimensions, which are the ability to read emotions, to represent the views of others, interest in communication with others, the activation of personal relations, taking into account differences and controlling social prejudice, working to generate interpretations and alternatives, and identifying the consequences of an event and the available options. The sample of the study consisted of (126) randomly selected undergraduate and graduate students. The results of the study showed that the level of ethical sensitivity among Princess Alia University College Students was low, and there were statistically significant differences in the level of ethical sensitivity due to specialization, in favor of humanities students, as well as statistically significant differences in the level of ethical sensitivity due to the educational level, in favor of master's students.
\end{abstract}

Keywords: Ethical sensitivity, Princess Alia university college, Moral sensitivity, Personal relations, Social prejudice.

Citation | Bilal Adel Al-Kateeb; Fatima Raqqad; Nisreen Shamayleh; Fatima Abdelhadi Zainelabdin; Amaal Al Masri (2021) The Level of Ethical Sensitivity among Jordanian University Students According to their Educational Level \& Specialization. Journal of Education and e-Learning Research, 8(4): 385-394. History:

Received: 16 August 2021

Revised: 20 September 2021

Accepted: 22 October 2021

Published: 17 November 2021

Licensed: This work is licensed under a Creative Commons

Attribution 3.0 License $(\mathrm{cc})$

Publisher: Asian Online Journal Publishing Group
Acknowledgement: All authors contributed to the conception and design of the study.

Funding: This study received no specific financial support

Competing Interests: The authors declare that they have no conflict of interests.

Transparency: The authors confirm that the manuscript is an honest, accurate, and transparent account of the study was reported; that no vital features of the study have been omitted; and that any discrepancies from the study as planned have been explained.

Ethical: This study follows all ethical practices during writing.

\section{Contents}

1. Introduction

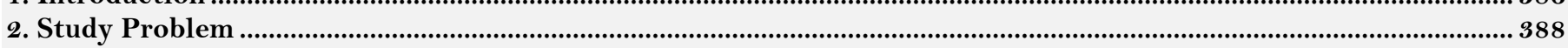

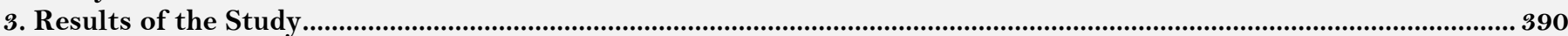

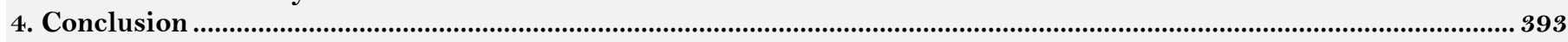

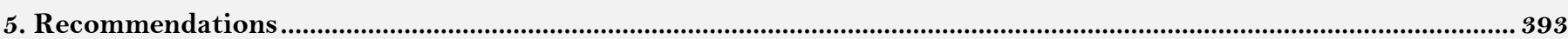

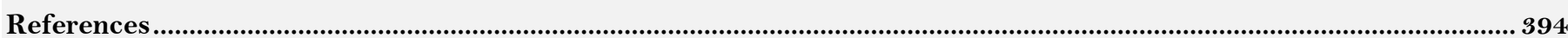




\section{Contribution of this paper to the literature}

This study helps in enlightening those in charge of youth affairs, officials and educators, of the necessity of adopting appropriate programs, curricula and methods for developing and rooting morals among university youth. The researchers expect that this study will benefit societal institutions such as schools, universities and mosques to play their role in the moral growth process of students, through seminars, programs, courses and activities, and provide opportunities to discuss ethical issues.

\section{Introduction}

Lawrence Kohlberg's theory of morality builds on and reconsiders the work of Piaget and, crucially, offers a method to measure a person's level of moral judgment; similar to Piaget's viewpoint, Kohlberg relied on the principle of justice to provide a basis for understanding universal moral judgments (Al-Ghamdi, 1997).

Kohlberg and Piaget both emphasized the importance of cognitive growth as the basis of moral growth and noted that there is an educational aspect to moral judgment, alongside the ethical concepts of the culture of love, justice, and power. Kohlberg also believed that a person's age is an essential factor in the development of ethics and that justice is a fundamental concept of moral growth and necessary for the achievement of social equilibrium between individuals and within societies. However, Kohlberg believed that peer interaction works to eliminate selfcenteredness rather than to increase emotional involvement, as Piaget argued.

In his moral judgment theory, Kohlberg developed a set of developmental stages that an individual undergoes at different levels, beginning with the preconventional level. This level, which includes two stages, is based on obedience and utilitarianism; people then reach the second level, in which they comply with the ethics, laws, and customs of their society, in two stages: interpersonal relationships and social order. Some individuals can then develop beyond this level to the third level, which is characterized by independent thought and a sensitivity of moral judgment known as postconventional (Abu Ghazal, 2010).

The postconventional level goes beyond attention to rigid laws and social rules to focus on the underlying ethics of laws and adherence to ethical principles. Ethical judgments are more exalted than in the previous stages as they are not linked to laws; this level includes two stages: the morality of the social contract and the stage of universal ethical standards, where the individual's goals in these two phases are based on the values of mercy, tolerance, justice, equality, equality of opportunity and human well-being (Clopton \& Sorell, 1993).

Kohlberg assessed individuals' moral growth using a specific moral dilemma, in which he presented a story to test subjects and asked them what they would do to help a child bring medicine to his mother, given the child's inability to buy the medicine, by offering a range of ethical and less ethical choices and asking the subjects to justify why they chose those options.

Although all ethical choices can be seen as a personal decision, some see them as economically motivated or as moral choices governed by social relations or professional standards. However, the ability to identify the moral dilemma, including its impact on others' actions, is an important point in the ethical development level of individuals, which later became known as ethical sensitivity (Swaner, 2004).

The American psychologist James Rest, one of the leading scientists in evolutionary and moral psychology interested in the development of Kohlberg's work, developed a research group (Minnesota) together with his colleagues Darcia Narvaez, Muriel Bebeau, and Stephen Thoma. They focused on creating a moral reasoning model, through which they proved that ethical sensitivity is one of the most important components of a moral perspective (Rest, Narvaez, Bebeau, \& Thoma, 1999). Ethical sensitivity generally is the ability to express an initial view of the moral position at the moment of the situation. It means to behave towards it in a decent, ethical manner, defined by Rest (1983) as the ability to interpret the moral position and identify aspects of the moral issue.

According to Kirsi Tirri and Nokelainen (2011), moral sensitivity means to approach a situation in an ethical manner. The ability to perceive and interpret events in a way that leads to moral action (Weaver, Morse, \& Mitcham, 2008) is the ability to identify critical aspects of the positives and negatives of a situation and to build a plan to respond to them. It is a crucial part of decision-making, which builds on the skills of empathy, understanding, and care to identify those affected by the decision and responsibly move to help others.

The concept of moral sensitivity is the ability to instantaneously react to occurrences in an ethical way; it requires that a person be able to perceive and interpret events in a way that leads to moral action and that the person possesses a measure of sensitivity and the ability to perceive different ways to respond to a situation. Hence, the characteristics of individuals who have a high level of moral sensitivity include sensitivity in their dealings with others, as well as empathy and good communication skills; these concepts are closely related to social intelligence as described by Goleman (2001), which can be defined as the ability to have good relations with others and permit their assistance (Albrecht, 2006).

Rest and his colleagues believe that moral sensitivity has three dimensions, which are expressed through actions that individuals take in response to situations; they identify actions that can help a person who needs moral assistance. The dimensions can be identified as follows:

1. Autonomy:

It is essential to know that the actions we take help the person to achieve independence. It describes how we

judge our competence in service delivery, and how we identify priorities that will help us maintain this person's independence.

2. Giving Benefit to Others (Beneficence):

This is done by considering whether the plan we offer will make the situation better, prevent damage that would have occurred, or offer a chance for psychotherapy.

3. Justice:

This is done by balancing the plan with the needs of the work and with the community's needs in general, taking into account the health conditions of the subject, and his status in the family and with his friends, peers, and relatives.

Narvaez (2001) argued that ethical sensitivity means to obtain information about the moral status, and to organize and interpret this information; not only data about the events that occur, but also the emotions gained at the moment of the event in the light of previous knowledge about it and its relationship to memory, as well as the 
characteristics of the individual. Ethical sensitivity includes a set of skills that individuals must have to be described as ethically sensitive, which can be expressed as follows:

Reading and Expressing Emotion:

Emotional reading is the ability to identify the needs and emotions of the self and others (i.e., both intrapersonal and interpersonal skills) and know when and how to express feelings appropriately. This is one of the most critical factors that contributes to socialization; reading and expressing emotions is a requirement of successful communication, and significantly contributes to solving problems and conflicts.

Representing the Views of Others:

This skill includes the ability to understand multiple points of view of different situations or events; thinking about how others feel is essential for the development of communication and problem-solving skills associated with positive social behaviors. We need this skill to see both sides of a problem, it helps us understand how others see, and also helps us develop empathy with them.

Caring by Connecting to Others:

This skill is the ability to expand the sense of self-concern to include concern for others' interests; it also reflects the development of the sense of association with other groups of people, both globally and locally, and the experience of empathy or a sense of interest in others. The individual must be prepared and able to understand and interpret others' feelings, just as the individual explains their own feelings. When this skill is acquired, a person can make decisions that reflect care for others care, meet others' needs, and strengthen relations with them.

Activating Personal Relationships and Taking into Account Differences:

Working within a group, despite the differences among its members, involves understanding the psychology of differences where misunderstandings can exacerbate conflicts. The individual needs to understand the nature of diversity within the groups in which he or she operates, as well as the role of diversity in general and how it is represented in the differences in his life. Success in this skill is based on multiculturalism, or the ability to work in more than one context, such as a family, community, or homogeneous work environment. Therefore, it is important to know the different mechanisms of interaction, as well as the different perspectives, values, and cultures, to accomplish collective tasks, decision-making, and conflict resolution.

Controlling Social Bias:

Prejudice is part of human nature because we naturally prefer familiar things and familiar ways of thinking; it requires a conscious effort to rethink personal habits, behaviors, and speech, making the resulting behavior more respectful and just.

Working on Generating Interpretations and Alternatives:

Interpreting events and considering serious alternatives is based on the development of creative skills used to generate multiple interpretations of an event and multiple alternatives to deal with it, a necessary step in problem solving. Individuals often repeat the same mistakes because they can think of no other way to behave in the situation.

Identifying the Consequences of Action and Options:

This skill is based on understanding the relationships between events and their outcomes and then using this understanding to predict potentialities. It is essential to consider what the short-term or long-term consequences may entail.

Rest et al. (1999) proposed a set of measures that can be used to encourage the development of students' moral sensitivity in the classroom. They suggest providing feedback from the teacher to students about their level of moral sensitivity, training students to self-assess their attitudes towards ethical sensitivity, and encouraging attitudes that enhance moral sensitivity through presentations, homework, and practical projects, as well as focusing on creating discussions and forums that discuss ethical issues in a way that reflects the feelings and enables the exchange of experiences of the individuals in ethics training.

Studies have shown in general terms that training in ethics and moral issues serves to increase moral sensitivity. A study by Park, Kjervik, Crandell, and Oermann (2012) showed that the level of moral sensitivity of nursing students was higher than that of new students who had not yet been trained in dealings with patients.

Hébert, Meslin, Dunn, Byrne, and Reid (1990) also conducted a study in which students were asked to identify ethical issues from a short article; they found a difference in individuals' perceptions of the moral position, indicating differences in the level of ethical sensitivity.

Tirri, Nokelainen, and Holm (2008) conducted a study to measure the level of moral sensitivity among seventh, eighth, and ninth-grade students in Finland, using the ethical sensitivity questionnaire ESSQ. The researchers applied the questionnaire to a sample of (248) students, and the results of the study indicated a high level of moral sensitivity among students. The results also demonstrated statistically significant differences in the level of sensitivity between self-assured students and students who are not self-assured, in favor of self-assured students. There were also differences in the level of moral sensitivity attributed to the gender variable in favor of females. Finally, there were statistically significant differences according to the academic qualification variable, since the students with the highest academic abilities showed the highest level of moral sensitivity.

Zaki (2012) conducted a study aimed at preparing a training program based on emotional intelligence for preparatory stage students, according to the model of Goleman (2001); they studied the effectiveness of the proposed program in the development of emotional intelligence and the development of the determinants of ethical behavior (ethical sensitivity - moral judgment - moral realism - moral character). The study sample consisted of (270) male and female students aged between 13 and 14 years old. The study tools included the measure of emotional intelligence (Boyatzis \& Goleman, 2007) and made use of a T-test and analysis of mono-variance. The results of the study showed that the training program was effective in developing emotional intelligence and the four determinants of ethical behavior, in accordance with the Rest (1984) model of ethical behavior.

Nadaraja and Mustapha (2017) conducted a study to investigate the level of moral sensitivity of accounting students at the University of Malaysia and how this was affected by the teaching of ethics. The study, which made use of a questionnaire to measure the level of moral sensitivity, was distributed to (114) male and female accounting students before and after a course in ethics. The study results indicate that after the course the final-year 
accounting students had an understanding of the importance of ethics in general, and the ethics course also improved these students' moral sensitivity.

Stichter (2015) conducted a study to understand the effects of demographic variables on ethical sensitivity among accounting students in the United States. The ESSQ was applied to 246 students of accounting at a US university; the results of the study indicated that the level of moral sensitivity among students was low and that the demographic variables examined (religion, training in accounting, belief in the importance of ethics) did not show a statistically significant relationship with the level of moral sensitivity.

It is noted the findings of previous studies on the level of subjects' ethical sensitivity differed from study to study; Nadaraja and Mustapha (2017), for instance, affirm that the level of ethical sensitivity was high among their study sample, as did Tirri et al. (2008), but Stichter (2015) found that the level of moral sensitivity was low.

Stichter (2015) found that demographic variables did not have a statistically significant effect on the level of moral sensitivity. In contrast, Tirri et al. (2008) found statistically significant differences in sensitivity between self-assured students and students who were not self-assured, in favor of self-assured students. They also found differences in the level of moral sensitivity that could be attributed to the gender variable, in favor of females, as well as statistically significant differences according to the variable of academic qualification; the students with the highest academic abilities had the highest level of moral sensitivity.

The differences in the results of previous studies regarding the level of moral sensitivity highlights the need to conduct further research to examine the level of moral sensitivity and the impact of demographic variables; also, when reviewing previous studies on the subject of ethical sensitivity, not many Arab studies were found that dealt with the concept of moral sensitivity. Therefore, this study aims to explore the effect of demographic variables on ethical sensitivity and measure their level among Jordanian university students; specifically, the present sample is of students at Al Balqa Applied University at Princess Alia University College.

The study by Hébert et al. (1990) emphasized the existence of a difference between individuals' levels of moral sensitivity. Therefore, this study aimed to measure the level of moral sensitivity among university students to learn whether they differed from others.

\section{Study Problem}

The institutions of higher education, including universities, are responsible for preparing and training students; the first goal of higher education in Jordan is to prepare scientifically, intellectually and morally qualified citizens to perform their duty in the service of their country. To achieve this goal, educational institutions, especially universities, must train students to adapt to the future and contribute to scientific and practical development.

Ethical sensitivity is closely linked to the ethics of professions, which comprise the set of ethical norms that the individual is committed to in his profession, towards society as a whole, and towards himself (Johns \& Saks, 2005). It also includes a "systematic reflection on the ethical implications of decisions taken"; these consequences can be placed in the context of particular harm to those concerned, which are lofty standards of moral conduct, that is, "acceptable behavior of society in the right versus wrong context" (Nickles et al., 2005a).

Training students and developing their moral sensitivity skills raises their competence and enhances their selfconcept. It also develops their sense of professional ethics, encouraging them to help others and improve the working environment to overcome the obstacles they face at work, achieve productivity, raise their level of performance, and achieve good citizenship.

At Balqa Applied University (in partnership with a group of community institutions and forums), the students participate in events that enhance their understanding of their future role in building the country and their awareness of the reality of this role, including the Senior Pioneers Forum, the Volunteer Day activities, and the Forum of Future Builders. These events are organized under the umbrella of the Ministry of Culture, which emphasizes the need for university students to understand their future professional role, and to develop a sense of professional ethics and moral sensitivity appropriate to this future role.

Therefore, the current study seeks to investigate the level of moral sensitivity of the students of Princess Alia College of Al Balqa Applied University according to their stage of study and specialization by answering the following research questions:

1. What is the level of moral sensitivity among the students of Princess Alia College of Al Balqa Applied University?

2. Does the level of moral sensitivity of the students of Princess Alia College of Balqa Applied University depend on the student's specialty and course?

\subsection{The Importance of the Study}

It is very important to pay attention to the development of the ethical outlook of society, and one of the most important strata of society is university students, who form the core nucleus from which to prepare for the future of society. By preparing them properly, both ethically and intellectually, universities contribute to the ultimate goal of the development and advancement of society. This study contributes to a clarification of the concepts related to university students' ethical sensitivity in general and focuses on some issues related to these concepts. Furthermore, a paucity of Arab studies in this field was identified. Therefore, this study is considered a limited contribution in this field. This study aims to identify the differences in the level of moral sensitivity that can be attributed to certain student-related variables, thereby contributing to the knowledge of the impact of demographic variables on moral sensitivity. The present study also presents a standard that is new to Arab researchers, the ESSQ, which measures ethical sensitivity, and which will help specialists, researchers, and educators measure ethical sensitivity and explore the research opportunities it offers.

\subsection{Procedural Definitions}

Ethical Sensitivity: The ability to interpret the moral position and identify aspects of the moral issue (Rest, 1983), known procedurally as the degree to which the student obtains the measure of ethical sensitivity that was used to achieve the objectives of the current study. 
Students of Princess Alia College: They are all students enrolled in Princess Alia University College of Al Balqa Applied University, for the first semester of the year (2016/2017) in the bachelor's and master's degree programs, between the ages of 18 and 35 years, and who consent to take part in the study.

\subsection{The Study Determinants}

The following determinants will determine the possibility of generalizing the results of the present study:

- Sample: The study scale will be applied to male and female students at the Princess Alia University College of the Al Balqa Applied University (1 st, 2nd, 3rd, and $4^{\text {th }}$ years) undertaking undergraduate studies (first and second) as well as master's students.

- The study tool is the digital image of the Ethical Sensitivity Scale (ESSQ), which the researcher will adopt to achieve the objectives of the study and its indications of validity and reliability.

\subsection{Study Procedures}

Study Sample: The study sample consisted of (126) male and female students of the bachelor's and master's degree programs at Princess Alia University College for the first semester of the academic year 2016/2017; Table 1 shows the distribution of the study sample individuals according to the study variables (academic specialization, administrative specialization) and the educational level (BA, MA).

Table-1. Distribution of study sample according to specialization and level of education.

\begin{tabular}{|c|c|c|c|c|c|}
\hline Specialization & Level & $\mathbf{N}$ & Percentage & \multicolumn{2}{|c|}{ Total } \\
\hline \multirow{2}{*}{$\begin{array}{l}\text { Administrative } \\
\text { specialties }\end{array}$} & Bachelor & 41 & $33 \%$ & \multirow[t]{2}{*}{54} & \multirow[t]{4}{*}{126} \\
\hline & Master degree & 13 & $10 \%$ & & \\
\hline \multirow[t]{2}{*}{ Academic specialties } & Bachelor & 56 & $44 \%$ & \multirow[t]{2}{*}{72} & \\
\hline & Master degree & 16 & $13 \%$ & & \\
\hline
\end{tabular}

\subsection{Study Variables}

This study included a number of variables:

Independent variables:

1. The academic specialization has two categories (administrative specialties, academic specialties).

2. The academic level has two categories (bachelor's, master's).

Dependent variable: Ethical sensitivity has seven levels (ability to read emotions, representing the views of others, interest in communicating with others, activating personal relationships, taking differences into account and controlling social prejudice, working to generate interpretations, and determining event dependencies and solutions).

Study Tool: To achieve the objectives of the study, the ethical sensitivity scale questionnaire (ESSQ) was used, as developed by Narvaez (2001). It is used to measure the moral sensitivity of adults and adolescents and consists of (28) questions in seven dimensions, which are outlined below.

Narvaez (2001) developed this measure based on the theories of Rest and Brabeck et al. (2000) on moral sensitivity. Gholami and Tirri (2012a) used it on a sample of teachers to examine the scale's psychometric properties and explore the components and dimensions of the scale through global empirical analysis (CFA). The seven dimensions of the questionnaire are:

1. Reading Emotions: Demonstrates the ability to understand the emotions of others and identify their feelings; questions that measure this dimension are $(1,8,15,22)$.

2. Representing the views of others: Demonstrates the ability to represent multiple views of different situations or events; the questions that measure this dimension are $(2,9,16,23)$.

3. Interest in communicating with others: Demonstrates the ability to develop a sense of connection with other groups of people, globally and locally; the questions that measure this dimension are $(3,10,17,24)$.

4. Activating interpersonal relationships: Demonstrates the ability to recognize the nature of diversity within the groups in which he/she operates, as well as diversity in general; the questions that measure this dimension are $(4,11,18,25)$.

5. Considering differences and controlling social prejudice: Demonstrates the ability to review personal habits, actions, and speech; the questions that measure this dimension are $(5,12,19,26)$.

6. Working to generate interpretations and alternatives: Demonstrates the ability to generate interpretations and realistic alternatives and develop the creative skills used to generate multiple interpretations; the questions that measure this dimension are $(6,13,20,27)$.

7. Define event dependencies and potential solutions: Demonstrates the ability to understand the relationships between events and their results and can use it to determine potential solutions; the questions that measure this dimension are $(7,14,21,28)$.

\subsection{Development of the Questionnaire in the Jordanian Environment}

The questionnaire was first translated into Arabic and then presented to six arbitrators, four specialists in educational psychology and educational guidance and family, with a good English ability, and two specialists in English at Princess Alia High School, to ensure the accuracy of the translation. After examining the questionnaire in both English and Arabic, the arbitrators judged the measure to be appropriate. It measures what it is meant to measure, the instructions are clear and appropriate, and the translation was sound. They suggested some adjustments that the researcher took into account, i.e., the answer scale was changed from a seven-point scale to a five-point scale that contained staging (always, often, sometimes, rarely).

Second, Gholami and Tirri (2012a) empirical analysis of the components of the questionnaire indicated that the measure is valid for studying the seven dimensions of moral sensitivity as formulated in the model (theory); however, they suggested making an adjustment to four pairs of elements (questions). This change was adopted in the current study, which has increased the indicators of honesty. 
The validity of the questionnaire was verified by presenting it to six arbitrators with a specialization in education and psychology at Princess Alia College. They were asked to look at the measure of ethical sensitivity and make observations about the questionnaire in terms of whether the questions were appropriate for the target group (undergraduate and masters students), whether they were suitable to measure the dimensions, whether their meaning was clear, and any other appropriate remarks. The observations were unanimously adopted, some linguistic errors were corrected, and some vague words were replaced by other words that were clearer and more relevant to the Jordanian environment.

To verify the validity of the questionnaire, the researcher applied it to a survey sample consisting of (33) female and (19) male undergraduate students. Pearson correlation coefficients were extracted for each question and grouped with the according dimension. Accordingly, item 8, which belongs to the first dimension, was deleted, as well as item (17), of to the third dimension, and item (13), which belongs to the sixth dimension. Appendix 1 shows the questionnaire in its final form. The Pearson correlation coefficients were also extracted to compare the seven dimensions, as well as the questionnaire overall. Table 2 shows the results:

Table-2. Pearson correlation coefficients between the dimensions and the total score of the scale.

\begin{tabular}{|c|c|c|c|c|c|c|c|c|}
\hline Dimensions & $1^{\mathrm{st}}$ & $2^{\text {nd }}$ & $3^{\text {rd }}$ & $4^{\text {th }}$ & $5^{\text {th }}$ & $6^{\text {th }}$ & $7^{\text {th }}$ & Total score \\
\hline First & - & 0.73 & 0.59 & 0.81 & 0.78 & 0.72 & 0.68 & 0.85 \\
\hline Second & - & - & 0.62 & 0.82 & 0.80 & 0.76 & 0.62 & 0.79 \\
\hline Third & - & - & - & 0.77 & 0.64 & 0.81 & 0.75 & 0.86 \\
\hline Fourth & - & - & - & - & 0.61 & 0.80 & 0.72 & 0.77 \\
\hline Fifth & - & - & - & - & - & 0.75 & 0.58 & 0.84 \\
\hline Sixth & - & - & - & - & - & - & 0.63 & 0.88 \\
\hline Seventh & - & - & - & - & - & - & - & 0.80 \\
\hline
\end{tabular}

\subsection{Reliability of the Questionnaire}

The questionnaire's reliability was verified by testing a separate sample consisting of (40) students and retesting them two weeks later. The Pearson correlation coefficients were then calculated between their results at the separate times for each dimension of the study instrument, and were found to range between 81.0 and 88.0; the reliability coefficient was also calculated according to the Cronbach alpha formula, and ranged from 86.0 to 91.0. Table 3 shows the internal consistency coefficient and the stability both of the dimensions and of the questionnaire as a whole.

Table-3. Returns stability and internal consistency coefficients of the ethical sensitivity measure.

\begin{tabular}{|c|c|c|}
\hline Dimension & $\begin{array}{c}\text { Repetition } \\
\text { reliability }\end{array}$ & Internal consistency \\
\hline Reading Emotions & 0.85 & 0.87 \\
\hline Representing the views of others & 0.82 & 0.85 \\
\hline Attention to communication with others: & 0.86 & 0.87 \\
\hline Activation of personal relationships: & 0.88 & 0.86 \\
\hline Taking into account differences and controlling social prejudice: & 0.81 & 0.89 \\
\hline Work on generating interpretations and alternatives: & 0.84 & 0.90 \\
\hline Define event dependencies and options: & 0.82 & 0.91 \\
\hline Questionnaire as a whole & 0.85 & 0.88 \\
\hline
\end{tabular}

\subsection{Questionnaire Correction Method}

As the responses to the questionnaire are in the form of a 5-point Likert scale, the possible answers (always, often, sometimes, rarely, never) have been associated with the scores $(5-4-3-2-1)$ respectively. Thus, the possible scores on the ethical sensitivity questionnaire range between 25 (the lowest score that can be obtained) and 125 (the highest possible score). An average score on the questionnaire thus corresponds to a score of 75 .

To assess students' ethical sensitivity after extracting their mathematical averages, a mathematical equation was designed. The range between the lowest (1) and highest (5) response was four; this was divided by the number of categories into which the ethical sensitivity level was divided -3 (high, average, low). The resulting value (1.33) was used to be divide the level of ethical sensitivity into three categories:

From 1 to 2.33 indicates a low level of ethical sensitivity.

From 2.34 to 3.67 is an average level of ethical sensitivity.

From 3.67 to 5 indicates a high ethical sensitivity level.

\section{Results of the Study}

The results of the study are presented below according to the answers to the research questions.

The first research question was: "What is the level of moral sensitivity among the students at Princess Alia College of Al Balqa Applied University?"

To answer this question, the arithmetical averages and standard deviations of the responses were extracted for the combined dimensions and for the questionnaire as a whole, as shown in Table 4.

Table 4 shows that the fourth dimension: the activation of personal relationships, had the highest response with an average of (2.16) for the level of moral sensitivity and a standard deviation of (0.63), followed by the sixth dimension: work to generate explanations and alternatives, with an average of (2.13), and a standard deviation of (0.59), followed by the third dimension: attention to communication with others, with an average of (1.96) and a standard deviation of (0.51), followed by the second dimension: representing the views of others, with an average of (1.91) and a standard deviation of (0.58), followed by the first dimension: reading emotions, with an average of (1.73) and a standard deviation of (0.43), followed by the fifth dimension: controlling social prejudice, with an average of (1.86) and a standard deviation of (0.50); finally, the seventh dimension had the lowest score: define event dependencies and options, with an average of (1.73) and a standard deviation of (0.47). Each of the tested 
dimensions showed a low score on the ethical sensitivity scale. The average response across the entire questionnaire was low, with an average of (1.93) and a standard deviation of (0.37).

Table-4. The arithmetical averages and standard deviations of the responses for the dimensions and for the questionnaire as a whole.

\begin{tabular}{|c|c|c|c|c|c|}
\hline $\mathbf{N}$ & Dimension & Mean & $\begin{array}{l}\text { Standard } \\
\text { deviation }\end{array}$ & Rank & Level \\
\hline 1 & Reading emotions & 1.7274 & 0.43320 & 5 & Low \\
\hline 2 & Representing the views of others & 1.9125 & 0.57836 & 4 & Low \\
\hline 3 & Attention to communication with others & 1.9563 & 0.50986 & 3 & Low \\
\hline 4 & Activation personal relationships & 2.1618 & 0.62881 & 1 & Low \\
\hline 5 & Controlling social prejudice & 1.8620 & 0.49535 & 6 & Low \\
\hline 6 & Work to generate interpretations and alternatives & 2.1256 & 0.59036 & 2 & Low \\
\hline 7 & Define event dependencies and options & 1.7324 & 0.47435 & 7 & Low \\
\hline \multicolumn{2}{|c|}{ Questionnaire as a whole } & 1.9252 & 0.37067 & & Low \\
\hline
\end{tabular}

Next, the results were analyzed to answer the second question: "Does the level of moral sensitivity of the students of Princess Alia College of Balqa Applied University depend on the student's specialty and course?"

To examine the differences in the overall ethical sensitivity score caused by the effects of independent variables, the MANOVA test was performed to assess the effect of these variables (specialization, educational stage) on the respondents' total score, using the Wilks' Lambda test as part of the multivariate analysis test, as shown in Table 5:

Table-5. Wilks' Lambda test results for the impact of specialization and course stage on ethical sensitivity.

\begin{tabular}{c|c|c|c|c|c}
\hline Variable & Value & F test & Degrees of freedom / numerator & Df & Sig \\
\hline Specialization & 0.226 & $49.709^{\mathrm{a}}$ & 8.000 & 116.000 & $* 0.000$ \\
\hline Stage & 0.488 & $15.227^{\mathrm{a}}$ & 8.000 & 116.000 & $* 0.000$ \\
\hline
\end{tabular}

Note: * Statistical value at the significance level $(\alpha=0.05)$.

Table 5 shows statistically significant differences in the overall level of ethical sensitivity attributable to the specialization variable, as well as statistically significant differences due to the educational stage variable. Below, these results are broken down according to the study variables and the separate dimensions.

\subsection{The Impact of Specialization on the Level of Moral Sensitivity:}

To find the differences in the level of moral sensitivity that can be attributed to the specialization of the students at Balqa Applied University, the differences were examined for the responses to the questionnaire as a whole and for each dimension of sensitivity by examining the effect of specialization. Table 6 presents the arithmetic averages and standard deviations of the dimensions of sensitivity according to each specialization category:

Table-6. The arithmetic averages and standard deviations of the responses according to the specialization variable for each dimension of ethical sensitivity.

\begin{tabular}{|c|c|c|c|c|}
\hline Dimension & Dimension (category) & Mean & Standard deviation & $\mathbf{N}$ \\
\hline \multirow{3}{*}{ First } & Administrative specialties & 1.4111 & 0.33740 & 54 \\
\hline & Humanitarian specialties & 1.9646 & 0.33509 & 72 \\
\hline & Total & 1.7274 & 0.43320 & 126 \\
\hline \multirow{3}{*}{ Second } & Administrative specialties & 1.5481 & 0.40035 & 54 \\
\hline & Humanitarian specialties & 2.1858 & 0.54086 & 72 \\
\hline & Total & 1.9125 & 0.57836 & 126 \\
\hline \multirow{3}{*}{ Third } & Administrative specialties & 1.6333 & 0.42869 & 54 \\
\hline & Humanitarian specialties & 2.1985 & 0.42625 & 72 \\
\hline & Total & 1.9563 & 0.50986 & 126 \\
\hline \multirow{3}{*}{ Fourth } & Administrative specialties & 1.7222 & 0.48900 & 54 \\
\hline & Humanitarian specialties & 2.4915 & 0.51030 & 72 \\
\hline & Total & 2.1618 & 0.62881 & 126 \\
\hline \multirow{3}{*}{ Fifth } & Administrative specialties & 1.5963 & 0.47819 & 54 \\
\hline & Humanitarian specialties & 2.0613 & 0.40909 & 72 \\
\hline & Total & 1.8620 & 0.49535 & 126 \\
\hline \multirow{3}{*}{ Sixth } & Administrative specialties & 1.7630 & 0.53704 & 54 \\
\hline & Humanitarian specialties & 2.3975 & 0.47257 & 72 \\
\hline & Total & 2.1256 & 0.59036 & 126 \\
\hline \multirow{3}{*}{ Seventh } & Administrative specialties & 1.4593 & 0.37190 & 54 \\
\hline & Humanitarian specialties & 1.9372 & 0.44002 & 72 \\
\hline & Total & 1.7324 & 0.47435 & 126 \\
\hline \multirow{3}{*}{ Total } & Administrative specialties & 1.5907 & 0.23752 & 54 \\
\hline & Humanitarian specialties & 2.1760 & 0.22567 & 72 \\
\hline & Total & 1.9252 & 0.37067 & 126 \\
\hline
\end{tabular}

Table 6 illustrates that there are apparent differences in the averages according to the variable specialization. To analyze the effect of the specialization variable on each dimension of the scale, a variable variance analysis (MANOVA) was carried out, and the results are shown in Table 7. 
Table-7. Results of the Multivariate Analysis Test (MANOVA) for the impact of specialization on ethical sensitivity.

\begin{tabular}{|c|c|c|c|c|c|c|c|}
\hline Source & $\mathbf{N}$ & Dependent variables & Sum of squares & Df & Mean & F test & Sig* \\
\hline \multirow{8}{*}{ Specialization } & 1 & Read emotions & 9.453 & 1 & 9.453 & 83.689 & 0.000 \\
\hline & 2 & Represent the views of others & 12.548 & 1 & 12.548 & 53.167 & 0.000 \\
\hline & 3 & Attention to communication with others & 9.855 & 1 & 9.855 & 53.977 & 0.000 \\
\hline & 4 & $\begin{array}{l}\text { Activate personal relationships and take into account } \\
\text { differences }\end{array}$ & 18.262 & 1 & 18.262 & 72.668 & 0.000 \\
\hline & 5 & Control social prejudice & 6.671 & 1 & 6.671 & 34.464 & 0.000 \\
\hline & 6 & Work on generating interpretations and alternatives & 12.424 & 1 & 12.424 & 49.471 & 0.000 \\
\hline & 7 & Define event dependencies and options & 7.049 & 1 & 7.049 & 41.472 & 0.000 \\
\hline & 8 & Total & 10.568 & 1 & 10.568 & 198.387 & 0.000 \\
\hline \multirow{8}{*}{ Error } & 1 & Read emotions & 14.006 & 124 & 0.113 & & \\
\hline & 2 & Represent the views of others & 29.265 & 124 & 0.236 & & \\
\hline & 3 & Attention to communication with others & 22.640 & 124 & 0.183 & & \\
\hline & 4 & $\begin{array}{l}\text { Activate personal relationships and take into account } \\
\text { differences }\end{array}$ & 31.162 & 124 & 0.251 & & \\
\hline & 5 & Control social prejudice & 24.001 & 124 & 0.194 & & \\
\hline & 6 & Work on generating interpretations and alternatives & 31.142 & 124 & 0.251 & & \\
\hline & 7 & Define event dependencies and options & 21.077 & 124 & 0.170 & & \\
\hline & 8 & Total & 6.606 & 124 & 0.053 & & \\
\hline \multirow{8}{*}{ Total adjusted } & 1 & Read emotions & 23.458 & 125 & & & \\
\hline & 2 & Represent the views of others & 41.813 & 125 & & & \\
\hline & 3 & Attention to communication with others & 32.495 & 125 & & & \\
\hline & 4 & $\begin{array}{l}\text { Activate personal relationships and take into account } \\
\text { differences }\end{array}$ & 49.424 & 125 & & & \\
\hline & 5 & Control social prejudice & 30.672 & 125 & & & \\
\hline & 6 & Work on generating interpretations and alternatives & 43.566 & 125 & & & \\
\hline & 7 & Define event dependencies and options & 28.126 & 125 & & & \\
\hline & 8 & Total & 17.174 & 125 & & & \\
\hline
\end{tabular}

Note: $*$ The value of the statistical function at the level of significance $\alpha=0.05$

Table 7 indicates that there are statistically significant differences in the effect of specialization on each of the sensitivity dimensions, as well as on the total degree of sensitivity; the table of mathematical averages shows that students in the humanitarian disciplines exhibit higher levels of ethical sensitivity than students in administrative disciplines.

\subsection{The Impact of Educational Stage on the Level of Moral Sensitivity:}

The impact of the educational stage on the differences in the responses was examined with regard to the questionnaire as a whole and each dimensions of sensitivity; Table 8 shows the mathematical averages and the standard deviations of the dimensions of sensitivity according to the educational stage categories.

Table-8. Mathematical averages and standard deviations of the responses by educational stage for each dimension of ethical sensitivity.

\begin{tabular}{|c|c|c|c|c|}
\hline Dimension & Dimension (category) & Mean & Standard deviation & $\mathbf{N}$ \\
\hline \multirow{3}{*}{ First } & Bachelor & 1.6933 & 0.41203 & 97 \\
\hline & Master & 1.8414 & 0.48808 & 29 \\
\hline & Total & 1.7274 & 0.43320 & 126 \\
\hline \multirow{3}{*}{ Second } & Bachelor & 1.8287 & 0.55235 & 97 \\
\hline & Master & 2.1931 & 0.58428 & 29 \\
\hline & Total & 1.9125 & 0.57836 & 126 \\
\hline \multirow{3}{*}{ Third } & Bachelor & 1.8669 & 0.47454 & 97 \\
\hline & Master & 2.2552 & 0.51795 & 29 \\
\hline & Total & 1.9563 & 0.50986 & 126 \\
\hline \multirow{3}{*}{ Fourth } & Bachelor & 2.0329 & 0.56328 & 97 \\
\hline & Master & 2.5931 & 0.65352 & 29 \\
\hline & Total & 2.1618 & 0.62881 & 126 \\
\hline \multirow{3}{*}{ Fifth } & Bachelor & 1.7630 & 0.47284 & 97 \\
\hline & Master & 2.1931 & 0.42589 & 29 \\
\hline & Total & 1.8620 & 0.49535 & 126 \\
\hline \multirow{3}{*}{ Sixth } & Bachelor & 2.0600 & 0.60003 & 97 \\
\hline & Master & 2.3448 & 0.50680 & 29 \\
\hline & Total & 2.1256 & 0.59036 & 126 \\
\hline \multirow{3}{*}{ Seventh } & Bachelor & 1.6524 & 0.46085 & 97 \\
\hline & Master & 2.0000 & 0.42426 & 29 \\
\hline & Total & 1.7324 & 0.47435 & 126 \\
\hline \multirow{3}{*}{ Total } & Bachelor & 1.8419 & 0.33606 & 97 \\
\hline & Master & 2.2038 & 0.34885 & 29 \\
\hline & Total & 1.9252 & 0.37067 & 126 \\
\hline
\end{tabular}

Table 8 indicates that there are apparent differences in the averages according to the educational stage variable. To analyze the effect of the educational stage variable on each dimension of the scale, a variable variance analysis (MANOVA) was carried out. 
Table-9. Results of the multiple analysis of variance (MANOVA) test for the effect of the school stage on moral sensitivity

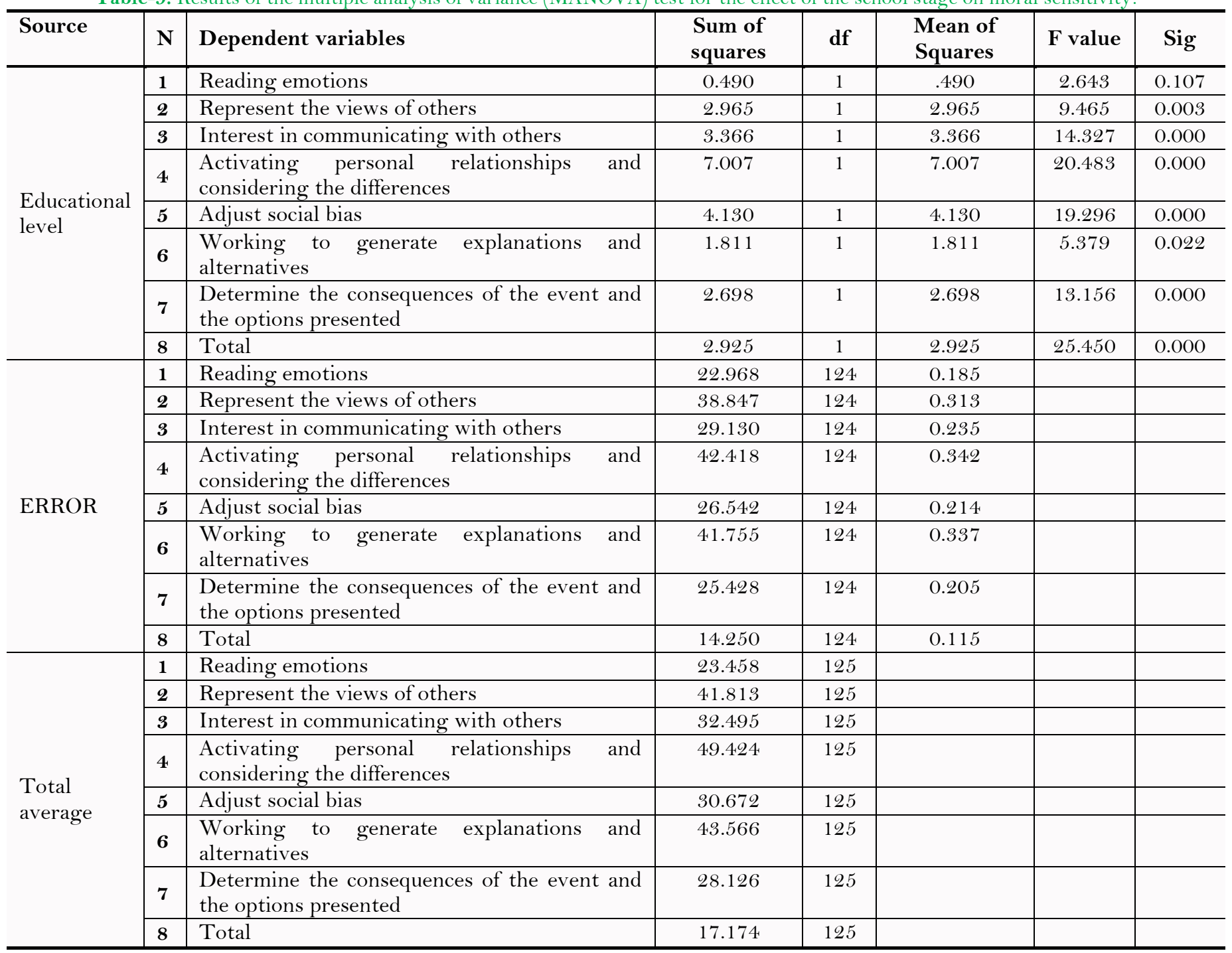

Table 9 indicates that there are statistically significant differences for the impact of the school stage in each of the dimensions of sensitivity and the total degree of sensitivity. Looking at the table of arithmetic averages, it is noted that students from the master's stage have outperformed students from the bachelor's stage.

\section{Conclusion}

The results of the first question, regarding the level of ethical sensitivity exhibited by students at Princess Alia College of Al Balqa Applied University, indicated that the fourth dimension: activation of personal relations, received the highest response, although still displaying a low level of moral sensitivity. This was followed by the seventh dimension: work to generate interpretations and alternatives, then by the third dimension. In the fourth place came the second dimension: representing the views of others, which was followed by the first dimension: reading emotions. Ranked sixth was the fifth dimension: the control of social bias, and ranked last was the seventh dimension: the identification of the consequences of an event and possible alternatives. As a whole the students displayed a low level of ethical sensitivity.

One possible explanation for this low level is that ethical sensitivity reflects an advanced level of ethical behavior. A person must gain advanced experience and thus needs to be trained in situations that lead him or her to behave consistently with a high standard of ethical sensitivity.

Another reason may be the abandonment of the traditional family role in the development and modeling of ethical behavior. This may be linked, among other things, to the difficult economic circumstances of Jordanian society, which have caused the vast majority of people to be primarily concerned with their livelihood; it may also be due to the previously stated requirement of ethical sensitivity to work with a group despite the differences among its members and the necessity of understanding the psychology of differences, where misunderstandings can exacerbate conflict. It is important that the individual understands the nature of diversity within the groups in which he or she works, as well as diversity within himself, and how this is represented by different roles. These qualities are negatively influenced by the new neoliberal system that drives individuals to pursue wealth instead of practicing behaviors that help others - university students are being influenced by this culture that has begun to invade Jordanian society.

\section{Recommendations}

In light of the findings of the study, the following recommendations are made:

1. Conduct courses, workshops, and training programs to help students develop ethical behavior in general and ethical sensitivity in particular. The result of this study indicate a low level of moral sensitivity, and previous studies have indicated the possibility of ethical behavior training.

2. Conduct studies to examine the causal relationship between moral sensitivity and the economic conditions of Jordanian society.

3. Conduct studies to examine the level of ethical sensitivity of other groups of students as well as studies examining the relationship between ethical behavior dimensions and different variables. 


\section{References}

Abu Ghazal, M. (2010). Theories of growth and their educational applications. Amman, Jordan: Dar Al-Masirah for Publishing, Printing, and Distribution.

Al-Ghamdi, H. (1997). Lifelong growth psychology. Jaddah, Saudi Arabia: Thought House.

Albrecht, K. (2006). Social intelligence.The new science of success. San Francisco, CA: Jossey-Bass.

Boyatzis, R. E., \& Goleman, D. (2007). Emotional competency inventory. Boston: The Hay Group Transforming Learning.

Brabeck, M. M., Rogers, L. A., Sirin, S., Hendersen, J., Benvenuto, M., \& Weaver, M. (2000). Increasing ethical sensitivity to racial and gender intolerance in schools: Development of the racial ethical sensitivity test. Ethics and Behavior, 1O(2), 119-137. Available at: https://doi.org/10.1207/s15327019eb1002_02.

Clopton, N. A., \& Sorell, G. T. (1993). Gender differences in moral reasoning: Stable or situational? Psychology of Women Quarterly, 17(1), 85101. Available at: https://doi.org/10.1111/j.1471-6402.1993.tbo0678.x.

Gholami, K., \& Tirri, K. (2012a). The cultural dependence of the ethical sensitivity scale questionnaire: The case of Iranian Kurdish teachers. Education Research International, 2012. Available at: http://dx.doi.org/10.1155/2012/387027.

Goleman, D. (2001). Emotional intelligence: Issues in paradigm building. In C. Cherniss 60 and D. Goleman (Ed's.), The Emotionally Intelligence Workplace. San Francisco: Jossey-Bass.

Hébert, P., Meslin, E. M., Dunn, E. V., Byrne, N., \& Reid, S. R. (1990). Evaluating ethical sensitivity in medical students: Using vignettes as an instrument. Journal of Medical Ethics, 16(3), 141-145. Available at: https://doi.org/10.1136/jme.16.3.141.

Johns, G., \& Saks, A. (2005). Organizational behavior: understanding and managing life at work: Pearson Prentice Hall.

Nadaraja, S. R., \& Mustapha, M. (2017). Ethical sensitivity of accounting students: Evidence from Malaysia. International Review of Management and Marketing, 7(1), 373-378.

Narvaez, D. (2001). Ethical sensitivity. activity booklet 1. Retrieved from: http://www.nd.edu/ dnarvaez. [Accessed March 2 2007].

Nickles, S., Furgal, C., Castleden, J., Armstrong, B., Buell, M., Dillion, D., . . Moss-Davies, P. (2005a). Unikkaaqatigiit-putting the human face on climate change-perspectives from Aklavik. Inuvialuit Settlement Region Joint publication of Inuit Tapiriit Kanatami, Nasivvik Centre for Inuit Health and Changing Environments at University Laval and the Ajunnginiq Centre a the National Aboriginal Health Organization, Ottawa

Park, M., Kjervik, D., Crandell, J., \& Oermann, M. H. (2012). The relationship of ethics education to moral sensitivity and moral reasoning skills of nursing students. Nursing Ethics, 19(4), 568-580. Available at: https://doi.org/10.1177/0969733011433922.

Rest, J. R. (1983). Morality. In Flavell, J. and Markman, E. (Eds.), Handbook of Child Psychology, Cognitive Development, Mussen, P. (ed.) (4th ed. Vol. 3). New York: Wiley.

Rest, J. R. (1984). Research on moral development: Implications for training counseling psychologists. The Counseling Psychologist, 12(3), 1929. Available at: https://doi.org/10.1177/0011000084123003.

Rest, J. R., Narvaez, D., Bebeau, M., \& Thoma, S. (1999). Postconventional moral thinking: A neo-Kohlbergian approach. Mahweh, New Jersey: Lawrence Erlbaum Associates.

Stichter, R. L. (2015). An analysis of how demographics affect accounting students' ethical sensitivity. Christian Business Academy Review, 10.

Swaner, L. E. (2004). Educating for personal and social responsibility: A review of the literature. Liberal Education, 91(3), $14-21$.

Tirri, K., \& Nokelainen, P. (2011). Measuring multiple intelligences and moral sensitivities in education(2011) Retrieved from: http://dx.doi.org/10.1007/978-94-6091-758-5.

Tirri, K., Nokelainen, P., \& Holm, K. (2008). Ethical sensitivity of Finnish Lutheran 7th - 9th graders, in Getting Involved: Citizenship Development and Sources of Moral Values, F. K. Oser and W. Veuglers, Eds. (pp. 327-341). Rotterdam, The Netherlands: Sense Publishers.

Weaver, K., Morse, J., \& Mitcham, C. (2008). Ethical sensitivity in professional practice: Concept analysis. Journal of Advanced Nursing, 62(5), 607-618. Available at: https://doi.org/10.1111/j.1365-2648.2008.04625.x.

Zaki, H. M. (2012). Effectiveness of a training program based on emotional intelligence in developing ethical sensitivity. Unpublished Ph.D. Thesis, Benha University, Egypt. 